\title{
SEMI-ACTIVE SUSPENSION INFLUENCE ON COMFORT SENSATION OF A VEHICLE OCCUPANT
}

\author{
Vidas Žuraulis, Robertas Pečeliūnas, Ginas Jakutis \\ Vilnius Gediminas Technical University \\ E-mail: vidas.zuraulis@vgtu.lt, robertas.peceliunas@vgtu.lt, \\ ginas.jakutis@stud.vgtu.lt
}

Received 2014-06-10, accepted 2014-09-10

This article presents an analysis of a modern-day vehicle semi-active suspension performance impact on comfort properties of its occupant. Vehicles chosen for the investigation had two different suspension-driving options, characterized as Comfort and Sport modes. These options change such vehicle parameters as suspension stiffness, algorithm of gearbox operation, and sensitivity of the steering system. Altering these two modes while driving at different speeds and on different road surfaces, vertical accelerations, affecting the occupant seat, were measured. Experiments and data processing were carried out according to ISO 2631-1 standard. After filtering the aforementioned vertical accelerations, the occupant comfort sensation was expressed as the vibration dose value (VDV) and the root mean square (RMS) of vibration acceleration value. Once the fast Fourier transform (FFT) was applied and vertical accelerations were converted to the frequency domain, spectral analysis of accumulated measurements was performed. After evaluating the comfort of an occupant, a summary of the vehicle suspension-driving mode influence is presented.

Comfort, semi-active suspension, root mean square, vibration dose value, spectral analysis, ISO 2631-1.

\section{Introduction}

A classical suspension system of a vehicle has to provide a desirable level of ride quality by isolating road disturbances using spring-type elements and shock absorbers, and improve the road holding ability by preventing the wheels from losing the road contact. By their controllability, suspension systems may be classified into three groups: passive, semi-active and active suspension systems (Guglielmino et al., 2008).

A passive suspension system incorporates conventional elements such as coil, leaf, or gas springs and viscous dampers, and its vertical movement corresponds directly to road irregularities. Semi-active and active suspension systems are controlled electronically and can adjust vertical movements caused by varying road conditions. More precisely, a semi-active suspension features an electronically controlled shock absorber which may vary the damping ratio with a bandwidth around 30-40 Hz. The shock absorber acts as a dissipative element, 
allowing no energy introduction into the system, thus improving the ride sensation (Savaresi et al., 2010).

Sprung and unsprung mass oscillations during braking were investigated by Pečeliūnas et al., 2003; 2005. Studies focused primarily on mathematical algorithm composition, theoretical calculations, and various factor influence on vehicle oscillation characteristics during the braking process. Investigations incorporated numerical and analytical methods. Devised mathematical models provide feasibility of determining vehicle motion, assist investigations of road traffic accidents linked with vehicle braking processes.

Relationship between road roughness and driving safety, which can be perceived as a tire-road contact force, is discussed by Barbosa, 2011. Proper operation of a suspension system is critical in terms of safety when driving on a rough road surface even at lower speeds $(25 \mathrm{~km} / \mathrm{h})$. Critical speed values can be obtained after processing the evaluated suspension response to various road conditions.

Vibrations that affect vehicle occupants are closely linked with their comfort properties and possible health risks (Eger et al., 2008; Thamsuwan et al., 2013). The effect of vibrations on the comfort of intercity bus users were analyzed by Sekulić et al., 2013. Conducted experiments and computer simulations were represented by the root mean square (RMS) of different vibration acceleration values. Increasing the stiffness of the operator seat showed that RMS values can nearly double in magnitude, and even triple compared to those of rearmost passenger seats.

Common road surface assessment approaches include International Roughness Index (IRI) (Kertesz et al., 2007) and ISO 2631-5 standard specifications. The latter one enables investigators to appropriately evaluate comfort sensation of vehicle occupants, while IRI is mostly used as a measure of road quality.

Published articles focus mostly on working machinery and large-sized vehicles, as there is little known evidence of different road surface type influence on comfort properties of a light-vehicle occupant. In addition, there is no substantial proof of whether modern electronic suspension-driving options, labeled as Sport and Comfort modes, provide actual change in comfort parameters of vehicle occupants.

Different human vibration evaluation approaches used in experimental research and for data processing are provided in the Evaluation of human vibrations section. Vehicles with adjustable suspension-driving options, conditions they were tested in, as well as measured vertical acceleration value filtering are presented in the Experimental procedure segment. Additional frequency analysis, supplementing the RMS and vibration dose value (VDV) calculations, is described in the Results and discussion section, followed by research conclusions. 


\section{Evaluation of human vibrations}

The operator and passengers of a vehicle are constantly exposed to mechanical vibrations, arising from uneven road surfaces and vehicle component oscillations. These factors reduce the comfort sensation and can be rather harmful to vehicle occupants. Usually vibrations affect human body as a whole and are known as a whole-body vibration (WBV). A human body is affected by vibrations from such surfaces as floors, seats, armrests, whose frequency ranges from $0.5 \mathrm{~Hz}$ to $80 \mathrm{~Hz}$, inducing certain displacements known as vibration accelerations (ISO 2631-1).

Light vehicle occupants are mostly affected by vertical vibrations (conventionally the $z$ axis) due to road unevenness (Fig. 1a). These vibrations are commonly assessed as accelerations and are measured by a specially designed disc (Fig. 1b), positioned on a seat in accordance with ISO 10326-1 standard. The outer $250 \mathrm{~mm}$ diameter disc is flexible, while a thin metal inner $75 \mathrm{~mm}$ diameter disc serves as a mounting plate for an accelerometer (Stein et al., 2011). This type of assembly allows the outer disc to accommodate the shape of the seat, while the housing for the accelerometer remains unaffected.

a)

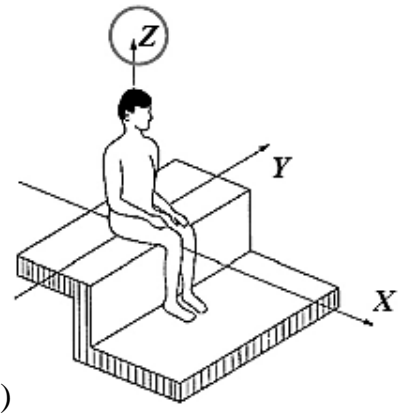

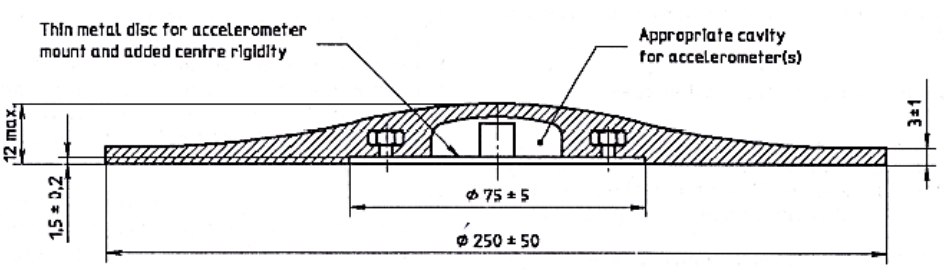

b)

Fig. 1. a) Vibration axes for whole-body vibration, centered at the seat; b) Design of flexible disc for mounting seat accelerometer(s) as defined in ISO 10326-1

Comfort can be described as the RMS of vibration acceleration value (Mansfield, 2005), which may be written as follows:

$$
R M S=\left(\frac{1}{T} \int_{0}^{T} a_{w}^{2}(t) d t\right)^{\frac{1}{2}},
$$

where: $T$-duration of measurement, s; $\mathrm{m} / \mathrm{s}^{2}$

$a_{w}(t)$ - instantaneous frequency-weighted acceleration value at time $t$, 
Instantaneous frequency-weighted acceleration value $a_{w}(t)$ describes a variable frequency effect to a human's body reaction to vibrations and can be expressed as follows (Rimell et al., 2007):

$$
a_{w}(t)=\left(\sum_{n}\left(W_{n} \cdot a_{n}\right)^{2}\right)^{\frac{1}{2}},
$$

where: $W_{n}$ - filtering weighting factor of a respective frequency band value; value, $\mathrm{m} / \mathrm{s}^{2}$.

$a_{n}$ - measured vibration acceleration value of a respective frequency band

Vibration dose value (VDV) is an additional parameter that can be used to estimate the magnitude of WBV (ISO 2631-1). It is employed when vibrations tend to change abruptly. The effectiveness of VDV value depends on the ratio of the maximal instantaneous acceleration value to the RMS value. This ratio is also known as the crest factor. For a clearer WBV evaluation, VDV is calculated by integrating the vibration energy over a shorter period of time and may be presented as follows:

$$
V D V=\left(\int_{0}^{T} a_{w}^{4}(t) d t\right)^{\frac{1}{4}} .
$$

Evaluations of human exposure to whole-body vibration can have alternative implementations. One such method is vibration spectrum analysis (ISO 8608). Here, the vertical acceleration values, affecting the human body, are converted from the time domain to the frequency domain. A practical and simple approach for this is the fast Fourier transform (FFT). After establishing vibration values in the frequency domain, it is convenient to assess vibration value differentiations.

\section{Experimental procedure}

In order to evaluate vehicle comfort properties and characteristics of different suspension-driving modes, two distinct 350 meter road sections were chosen. The road roughness for both sections is provided in Fig. 2.

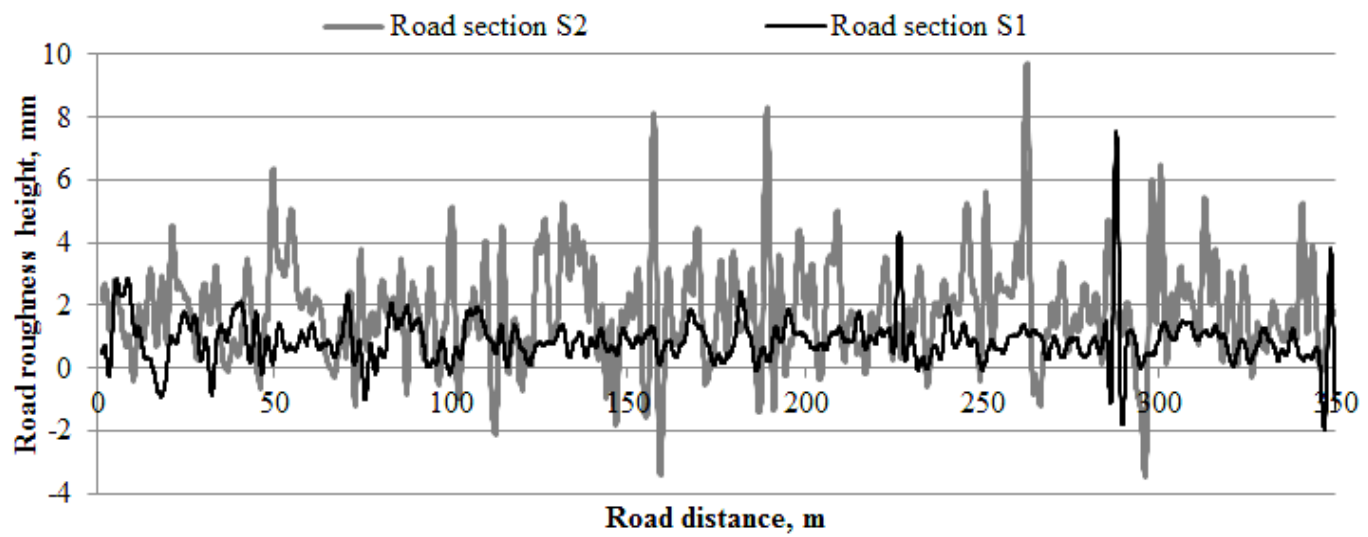

Fig. 2. Pavement roughness of selected experimental road sections 
Data of road roughness is used from Mobile Road Survey Laboratory RST 28. Road section S1 is assigned to A class in accordance with ISO 8608 standard, while road section S2 (C class) contains a rougher path with greater irregularities. These distinctions allow a clearer evaluation of vehicle comfort properties and driving characteristics.

Research experiments were executed to assess the vehicle semi-active suspension system adaptation to changes in road roughness. The vehicles chosen for the investigation along with their technical specifications are listed in Table 1. Although different suspension-driving options alter gearbox, steering system, and other auxiliary component operations, these parameters had no effect on experiment results, as travelling trajectories consisted of straight lines and vehicles were driven at a fixed speed using the autopilot function. Research-relevant parameters - suspension stiffness and damping efficiency - were altered by switching between suspension-driving modes.

Table 1. Vehicle technical specifications

\begin{tabular}{|l|l|l|l|}
\hline & $\begin{array}{l}\text { Mercedes-Benz E } \\
\text { 350 BlueTEC } \\
\text { 4MATIC }\end{array}$ & $\begin{array}{l}\text { Mercedes-Benz E } \\
\text { 280 CDI }\end{array}$ & \multicolumn{1}{|c|}{$\begin{array}{c}\text { Opel Insignia 1.6 } \\
\text { SIDI Turbo }\end{array}$} \\
\hline Produced since & 2013 & 2007 & 2013 \\
\hline Body type & Sedan & Station wagon & Sedan \\
\hline $\begin{array}{l}\text { Length, width, height, } \\
\mathrm{mm}\end{array}$ & $4879,1853,1474$ & $4888,1822,1505$ & $4842,1858,1498$ \\
\hline Engine power, $\mathrm{kW}$ & $185(3600 \mathrm{rpm})$ & $139(4000 \mathrm{rpm})$ & $125(4250 \mathrm{rpm})$ \\
\hline Engine torque, $\mathrm{N} \cdot \mathrm{m}$ & $\begin{array}{l}620(1600-2400 \\
\text { rpm })\end{array}$ & $\begin{array}{l}400(1400-3200 \\
\mathrm{rpm})\end{array}$ & $260(1650-4250 \mathrm{rpm})$ \\
\hline Wheelbase, mm & 2873 & 2854 & 2737 \\
\hline Front, rear track, mm & 1599,1605 & 1560,1552 & 1587,1590 \\
\hline Mass, kg & 1956 & 1844 & 1613 \\
\hline Tires & $245 / 45 \mathrm{R} 17$ & $225 / 55 \mathrm{R} 16$ & $225 / 55$ R17 \\
\hline $\begin{array}{l}\text { Suspension-driving } \\
\text { distinctive features }\end{array}$ & $\begin{array}{l}\text { Switching between Sport and Comfort } \\
\text { modes changes firmness of the } \\
\text { suspension as well as damping } \\
\text { adaptation, gear shifting, and steering } \\
\text { sensitivity }\end{array}$ & $\begin{array}{l}\text { FlexRide electronic } \\
\text { chassis control allows } \\
\text { drivers to switch between } \\
\text { Standard, Tour, and Sport } \\
\text { modes, altering vehicle's } \\
\text { acceleration, gear shifting, } \\
\text { damping effectiveness, } \\
\text { suspension and steering } \\
\text { characteristics }\end{array}$ \\
\hline & \multicolumn{2}{|l}{} \\
\hline
\end{tabular}

The special design disc (ISO 10326-1) was placed on the front passenger seat. The disc housed a Silicon accelerometer with a mass of 21 grams, sensitivity of $80 \mathrm{mV} / \mathrm{g}$, and a frequency response of $0-1500 \mathrm{~Hz}$ (Fig. 3a-1). Accelerometer data acquisition system Corrsys-Datron DAS-3 with a tuned sampling rate of 200 $\mathrm{Hz}$ was positioned on the rear passenger seat (Fig. 3a-2). 


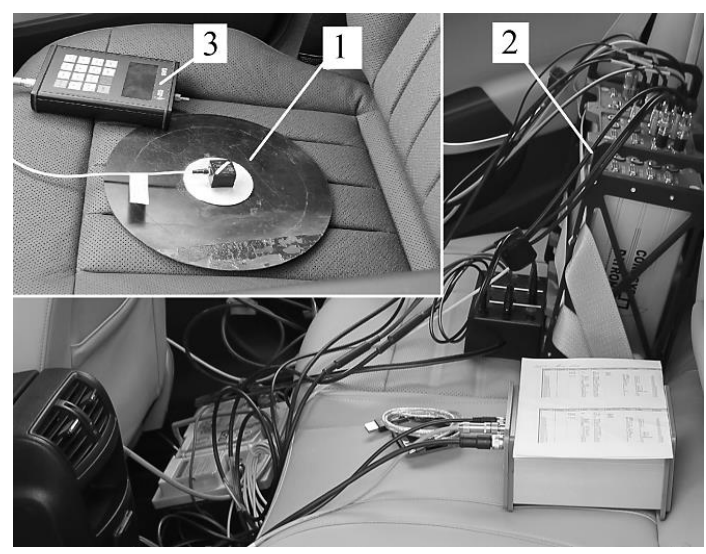

a)

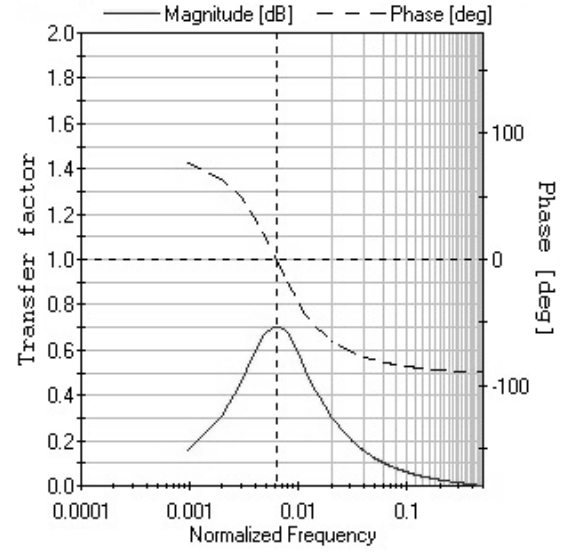

b)

Fig. 3. a) Measurement equipment used in experiments: 1 - flexible disc with a mounted seat accelerometer; 2 - data acquisition system; 3 - control panel; b) acceleration data filter graphical definition

Experiments were carried out employing the aforesaid vehicles and road segments S1 and S2, while driving at the speed values of $30,50,70$, and $100 \mathrm{~km} / \mathrm{h}$. For every respective speed value, the test was conducted twice - once in Comfort $(C)$ mode, and once in Sport $(S)$ mode. Data gathering of the established road section began once the required speed value was reached and set fixed using the autopilot function. A total of 8 tests per vehicle were performed.

To facilitate the estimation of whole-body vibration effect on vehicle occupants, the accumulated acceleration values must be filtered by discarding values lower than $0.5 \mathrm{~Hz}$ and higher than $80 \mathrm{~Hz}$. This is achieved by using a transfer function (Fig. 3b). The function highlights acceleration values in relevant frequency ranges, while suppressing the values in less relevant ranges. Phase lag is compensated correspondingly.

\section{Results and discussion}

Approaches chosen for the initial vehicle occupant comfort evaluation included determining VDV and the RMS of vibration acceleration values (ISO 2631-1). The RMS calculations indicated that between the two suspension-driving modes, $C$ mode exhibited lower vibrations and higher comfort only below $50 \mathrm{~km} / \mathrm{h}$ (Fig. 4). Distinct road section analysis revealed that greater discrepancies between $C$ mode and $S$ mode were noticed when driving on a rougher road section $\mathrm{S} 2$.

Depending on its suspension system operation algorithm, a vehicle can selfadjust to irregularities in spite of the selected suspension-driving mode. In such cases, the system attempts to maintain higher stability at the expense of comfort sensation. 

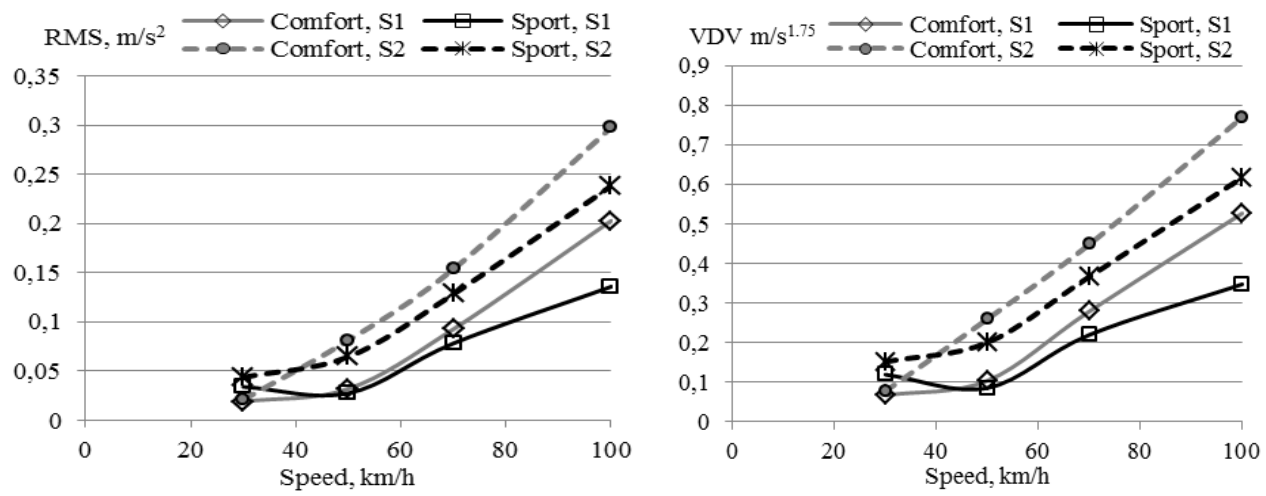

Fig. 4. Evaluated RMS and VDV values in various speed and road conditions

VDV tends to accumulate as the duration of measurement (time) increases, therefore it is less suitable to use it as an indicator of vehicle comfort. In pursuance of a clearer $C$ and $S$ mode effect on a vehicle occupant comfort, spectrum analysis was employed. After applying the fast Fourier transform (FFT), a power spectral density (PSD), displaying the test object reaction to external forces, was formed. Fig. 5 reveals the MB E 350 experiment results. Tests on a smoother surface road section $\mathrm{S} 1$ show little difference from the previous results, except for a $10 \%$ smaller distinction between $C$ and $S$ modes below $70 \mathrm{~km} / \mathrm{h}$.

Once the road roughness induced vertical accelerations are converted from the time domain to the frequency domain, it becomes possible to assess vertical vibration amplitudes more accurately. Driving at the lowest speed value of 30 $\mathrm{km} / \mathrm{h}$, an updated suspension system vehicle MB E 350 exhibited 2-5\% greater accelerations on $S$ mode than it did on $C$ mode. Conversely, driving at 50,70 , and $100 \mathrm{~km} / \mathrm{h}$, revealed that the numbers have swapped: driving on $C$ mode proved to be less comfortable, as $C$ mode accelerations were $21-45 \%$ (S1) and $20-27 \%$ (S2) greater than those of $S$ mode. It was determined that both suspension-driving modes experienced maximal acceleration values at the frequency of $2.5 \mathrm{~Hz}$, suggesting that $C$ mode provides greater comfort, since the intensities of oscillations are constant, only their amplitudes are larger. A frequency of $1.5 \mathrm{~Hz}$ indicates the natural frequency of a vehicle body, whereas a higher frequency signals the oscillations of the unsprung masses and was not established during the experiment.

Lowest PSD values were obtained during Opel Insignia tests. Compared to MB E 350 tests, Insignia's accelerations on the smoother road surface section S1 differed by $20 \%$, while on the rougher section S2 they differed by $29 \%$. PSD characteristics revealed the broadest tested vehicle frequency range of $1-2.5 \mathrm{~Hz}$, implying that the suspension is stiffer and damping elements act quicker than those of other vehicles, thus restraining the jounce motion.

The earlier edition MB demonstrated a $10 \%$ slighter difference in comfort properties when tested on $C$ and $S$ modes. Both suspension-driving modes in this vehicle tend to be modified with respect to comfortable driving experience, as opposed to sportiness. 


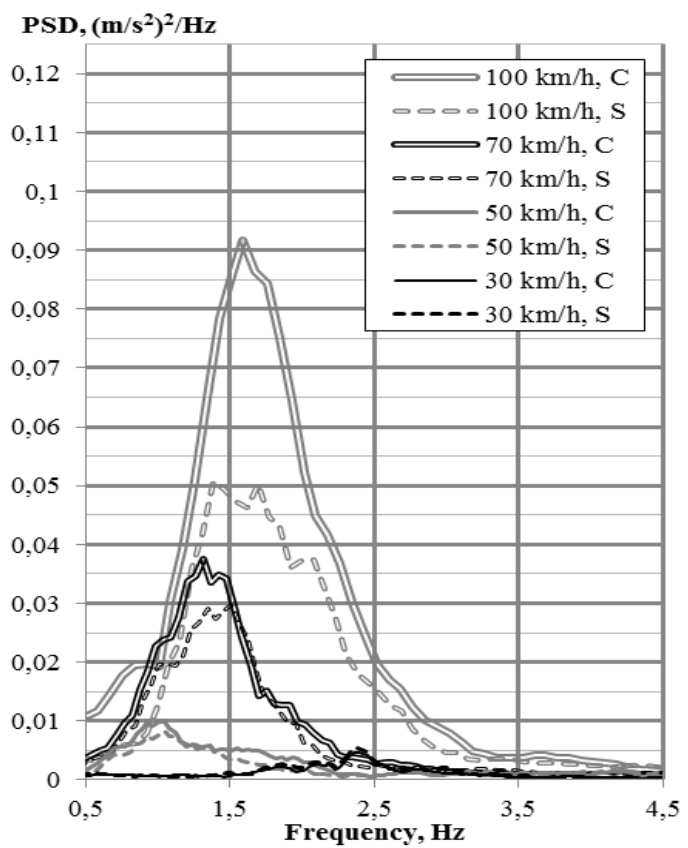

a)

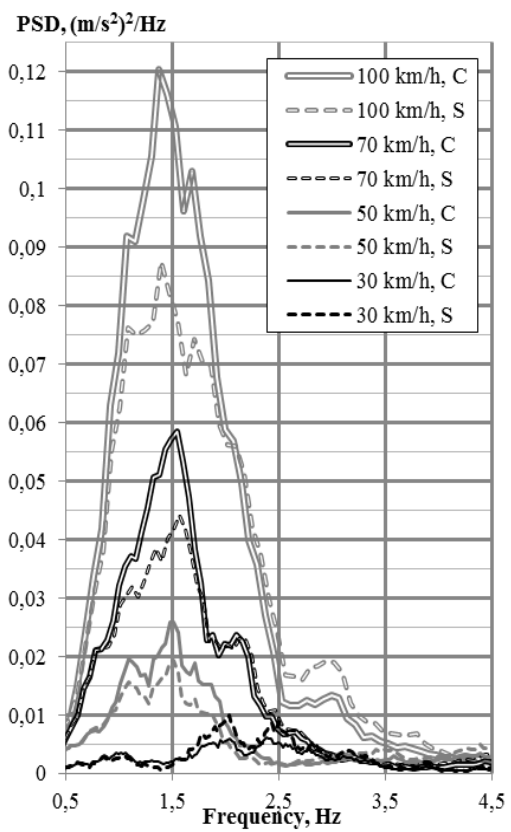

b)

Fig. 5. Acceleration energy contained within a frequency band (MB E 350): a) section S1; b) section $\mathrm{S} 2$

\section{Conclusions}

The performed investigation of semi-active suspension system parameters may be generalized in the following manner:

1. Conventional methods and standardized instructions on how to evaluate human exposure to vibrations from variable parameter suspensions do not yield entirely appropriate results, particularly due to vibration dose value accumulation over time.

2. Comfort sensation of an occupant of a semi-active suspension vehicle changes nonlinearly as the driving speed value is increased. Comfort sensation varies with road roughness and selected driving mode.

3. Frequency analysis is a suitable indicator of comfort sensation. Vibration amplitude differences are caused by suspension properties and are noticeable at the frequency range of $1-2.5 \mathrm{~Hz}$.

4. Compared to the latest edition of a semi-active suspension system, an earlier edition yields a 5-10\% smaller vibration sensation difference between Comfort and Sport modes.

5. Similar modern-day semi-active suspension systems with different suspension-driving options show that even Comfort mode can act as a sporty, stiff suspension in order to keep up with road irregularities and suppress the vertical occupant seat accelerations, hence maintaining optimal tire-road contact and ensuring traffic safety. 


\section{References}

1. Barbosa, R. S. 2011. Vehicle Dynamic Safety in Measured Rough Pavement. Journal of Transportation Engineering, 137(5), 305-310.

2. Eger, T.; Stevenson, J.; Boileauc, P.-É.; Salmoni, A. Predictions of health risks associated with the operation of load-haul-dump mining vehicles: Part 1Analysis of whole-body vibration exposure using ISO 2631-1 and ISO-2631-5 standards. International Journal of Industrial Ergonomics, 38, 726-738. DOI: 10.1016/j.ergon.2007.08.012.

3. Guglielmino, E.; Sireteanu, T.; Stammers, C. W.; Ghita, G.; Giuclea, M. 2008. Semi-active Suspension Control - Improved Vehicle Ride and Road Friendliness. London: Springer, 294 p. DOI: 10.1007/978-1-84800-231-9.

4. ISO 10326-1:1992. Mechanical Vibration - Laboratory Method for Evaluating Vehicle Seat Vibration - Part 1. International Organization for Standardization. Geneva.

5. ISO 2631-1:1997. Mechanical Vibration and Shock - Evaluation of Human Exposure to Whole Body Vibration - Part 1. International Organization for Standardization. Geneva.

6. ISO 8608:1995. Mechanical Vibration - Road Surface Profiles - Reporting of Measured Data. International Organization for Standardization. Geneva.

7. Kertesz, I.; Lovas, T.; Barsi, A. Measurement of road roughness by lowcost photogrammetric system. Commission $V, W G V / 1$.

8. Mansfield, N. J. 2005. Human Response to Vibrations. CRC Press, 256 p.

9. Pečeliūnas, R.; Lukoševičienè, O.; Prentkovskis, O. 2003. A mathematical model of the vibrating system equivalent to the vehicle in the mode of emergency braking / Robertas Pečeliūnas. Transport: journal of Vilnius Gediminas Technical University and Lithuanian Academy of Sciences, 18(3), 136-142.

10. Pečeliūnas, R.; Prentkovskis, O. 2006. Influence of shock-absorber parameters on vehicle vibrations during braking. Solid State Phenomena: Mechatronic Systems and Materials, 113, 235-240.

11. Rimell, A. N.; Mansfield, N. J. 2007. Design of Digital Filters for Frequency Weightings Required for Risk Assessments of Workers Exposed to Vibration. Industrial Health, 45, 512-519.

12.Savaresi, S. M.; Poussot-Vassal, C.; Spelta, C.; Sename, O.; Dugard, L. 2010. Semi-Active Suspension Control Design for Vehicles. Elsevier, 206 p.

13.Sekulić, D.; Dedavić, V.; Rusov, S.; Šalinić, S.; Obradović. 2013. Analysis of vibration effects on the comfort of intercity bus users by oscillatory model with ten degrees of freedom. Applied Mathematical Modelling, 37, 86298644. http://dx.doi.org/10.1016/j.apm.2013.03.060.

14. Stein, G. J.; Chmurny, R.; Rosik, V. 2011. Compact Vibration Measurement System for in-vehicle Applications. Measurement Science Review, 11(5), 154-159.

15. Thamsuwan O; Blood, R. P.; Ching, R. P.; Boyle, L.; Johnson, P. W. Whole body vibration exposures in bus drivers: A comparison between a high-floor coach and a low-floor city bus. International Journal of Industrial Ergonomics, 43, 9-17. http://dx.doi.org/10.1016/j.ergon.2012.10.003. 